University of Wollongong

Research Online

Faculty of Engineering and Information

Faculty of Engineering and Information

Sciences - Papers: Part A

Sciences

$1-1-2013$

Gestural interface technology in early childhood education: a framework for fully engaged communication

Holly Tootell

University of Wollongong, holly@uow.edu.au

Melinda Plumb

University of Wollongong, mplumb@uow.edu.au

Colin D. Hadfield

University of Wollongong, chadfiel@uow.edu.au

Linda Dawson

University of Wollongong, lindad@uow.edu.au

Follow this and additional works at: https://ro.uow.edu.au/eispapers

Part of the Engineering Commons, and the Science and Technology Studies Commons

Research Online is the open access institutional repository for the University of Wollongong. For further information contact the UOW Library: research-pubs@uow.edu.au 


\title{
Gestural interface technology in early childhood education: a framework for fully engaged communication
}

\author{
Abstract \\ Gestural Interface Technology (GIT) has changed the way technology is adopted in classrooms for all \\ ages. The accessibility of control through touch means that technology such as Apple's iPad can be used \\ in early childhood education. In this paper, we introduce a framework for fully-engaged communication, \\ developed from educational pedagogy and critical engagement in information systems. The intersection \\ of these dimensions creates a view of a GIT lifeworld approach which allows it to be used to understand \\ multiple layers of engagement that exist within an early childhood education environment. \\ Keywords \\ era2015 \\ Disciplines \\ Engineering | Science and Technology Studies

\section{Publication Details} \\ Tootell, H., Plumb, M., Hadfield, C. D. \& Dawson, L. (2013). Gestural interface technology in early childhood \\ education: a framework for fully engaged communication. 46th Hawaii International Conference on \\ System Sciences (HICSS), 2013 (pp. 13-20). Australia: IEEE.
}




\section{Gestural Interface Technology in Early Childhood Education: A framework for fully-engaged communication}

\author{
Holly Tootell \\ University of Wollongong \\ holly@uow.edu.au
}

\author{
Melinda Plumb \\ University of Wollongong \\ mplumb@uow.edu.au
}

\author{
Colin Hadfield \\ University of Wollongong \\ chadfield3@bigpond.com
}

\author{
Linda Dawson \\ University of Wollongong \\ lindad@uow.edu.au
}

\begin{abstract}
Gestural Interface Technology (GIT) has changed the way technology is adopted in classrooms for all ages. The accessibility of control through touch means that technology such as Apple's iPad can be used in early childhood education.

In this paper, we introduce a framework for fully-engaged communication, developed from educational pedagogy and critical engagement in information systems. The intersection of these dimensions creates a view of a GIT lifeworld approach which allows it to be used to understand multiple layers of engagement that exist within an early childhood education environment.
\end{abstract}

\section{Introduction}

There is high level of importance ascribed to the role of information and communication technologies (ICT) into various education policies. The integration of ICT is a key element in every learning area in the new Australian National Curriculum [1], the United States' National Association for the Education of Young Children 'Technology and Interactive Media as Tools in Early Childhood Programs' policy statement [2], and the United Kingdom's National Curriculum [3]. ICT in education is also promoted by the United Nations Educational Scientific and Cultural Organisation (UNESCO) as a way of addressing "access, inclusion and quality" [4] and the International Society for Technology in Education have produced a set of standards to assist in teachers being prepared to provide technology-supported learning opportunities for students [5].

Gestural Interface technologies are a subset of ICT. This paper provides a view on the impact Gestural Interface Technology (GIT) can have on engagement within early childhood education. It is timely research given the increasing trend towards adoption of devices with gestural interfaces, and the focus in curriculums for early childhood education on integrating technology.

\section{Background}

\subsection{Gestural Interface Technology}

Until recently most computing devices utilised what is commonly referred to as a WIMP (Windows, Icons, Mouse, and Pull-down menus) user interface. User input was provided via a keyboard and mouse or trackpad/trackball device for devices such as laptops and netbooks, and via a stylus/pen for devices such as tablets and smart phones.

Recently there has been a change in the paradigm of computing device user interfaces, in particular how users provide input to these devices. This new form of interaction is known as a gestural, or natural interface [6] and involves the user providing input to the device by using their fingers to create single and multiple touch gestures on the screen. This form of user interface is relatively new, with portable computing devices utilising it only becoming available to purchase since 2010. Computing devices that utilise a gestural user interface include Interactive Whiteboards, iPads and other tablet devices such as the Android-based Samsung Galaxy.

Gestural interfaces can be single touch or multiple touch sensing. In terms of the technologies to be examined in this research, iPads are multiple touch devices, whereas the Interactive Whiteboards can be single or multiple touch. For example, the SMART range of Interactive Whiteboards are split into the 600i series which are single touch, and the $800 \mathrm{i}$ series which are multiple touch [7].

Research is limited regarding the adoption and usability of devices utilising this form of interface in organisations and would benefit from further research. 
The introduction in April 2010 of the iPad by Apple, a touch-screen tablet, is seen as a major driving force in the growth of the tablet market, particularly when the sale of iPads represents approximately $76 \%$ of the total Australian tablet market [8]. In 20122.6 million Australians are using touch screen tablets and more than 11 million are expected to use one by 2016 [8].

Apple has historically been known for its presence in the education sector [9], with Apple's senior vice president of Worldwide Marketing stating at the March 2012 launch for the iBooks 2 software for iPads that "education is deep in Apple's DNA and iPads may be our most exciting education product yet" [10]. Many schools have been quick to adopt iPads, with more than 1.5 million already in use in educational programs worldwide [11]. In terms of student ownership of tablets, Catalano [12] found that in America $25 \%$ of college students own tablets, of which $63 \%$ of those are iPads, tripling from $7 \%$ in a single year. At the same time, $17 \%$ of high school seniors own tablets, quadrupling from $4 \%$. Today Apple remains a dominating force in the tablet market [13].

\subsection{The Use of Gestural Interface Technology in Education}

Much of the current literature pertaining to the use of tablet devices in education has focused on the use of tablets that are pre-iPad (i.e. available prior to April 2010) which utilised a stylus-based interface rather than the newer gestural interface. In regards to literature on IWBs, Smith et al. [14] note a lack of empirical academic literature available and advise caution in interpreting findings due to the use of informal and poorly documented research methodologies and quality of data. iPads, tablet devices and IWBs can all be classified as mobile computing devices (IWBs when mounted on a moveable stand [15]), although the majority of IWBs are wall-mounted.

Literature regarding the use of tablets in the K12 educational sector appears to be limited. Kennewell and Morgan [16] examined the use of tablets and laptops in loosely structured learning environments, with a focus on learning through play using ICT as they comment that 'playing around' is an effective way of learning certain ICT techniques and concepts and has the potential to contribute to knowledge. Oviatt et al. [17] studied the use of pendriven tablets in high school geometry students, and noted negatively that working with the tablet interface was slower than with a paper-based interface (p. 198).
These findings by Oviatt et al. [17] are in contrast to the findings of the study carried out by Ferrer et al. [18] where they examined the results of tablet usage in public schools in the region of Aragón (Spain). They asked the question "do tablet PCs contribute to reducing existing inequalities", and their findings concluded that tablet usage did indeed benefit students from disadvantaged socioeconomic and cultural environments in terms of academic results, and students with the worst academic records improved more in comparison with the rest of their classmates.

Milner's 2006 research [19] into tablets in K-12 speaks extravagantly about the "unmistakeable change" that tablets have brought to the learning process at Kent School and that it has spawned a "knowledge-thirsting culture". However the article is high on anecdotal evidence rather than empirical findings.

Although these findings illustrate the growing use of GIT in K-12 educational institutions, there is a significant gap in available academic empirical research on the use of iPads. Bebell et al. [20] wrote a small report on a nine-week randomised control trial examining the impact of iPads on kindergarten student's literacy skills. Their findings indicated no statistically significant differences in performance between the iPad and comparison setting, although notably the students using the iPad performed better in the 'Hearing and Recording Sounds in Words' test. The Manhattan Beach Unified School District [21] produced a performance review report containing statistics obtained from a survey administered to students, parents and teachers in regards to their iPad Pilot Project. They noted positive findings in areas such as student engagement, instructional differentiation, and that the $\mathrm{iPad}$ has created a more innovative place for learning. However there is no discussion of research methodology used or sample size in any of these studies, and the results have limited value.

According to Moseley et al. (1999 in [22]), the potential for the use of IWBs in primary school educational settings was recognised in the late 1990s. Authors such as Lee [23] reflect on the IWB as a significant development in the history of schooling.

Many authors have reported common benefits such as the creation and presentation of more attractive resources [14, 24-26] capturing and holding students' attention [14, 25], and the attainment of positive student perceptions and enthusiasm [25, 2729].

In regards to teacher perspectives, many authors report an enthusiasm $[29,30]$ but also a need for appropriate in-service training and professional 
development to support the use of the technology [14, $15,30,31]$ report findings that the touch-sensitive nature of IWBs facilitates a more efficient presentation and more professional delivery of multimedia resources. The IWBs creating an environment with a high level of student-teacher interaction was also noted by several authors [27-29, 32].

Beeland [15] conducted an action research study to determine the effect of the use of IWBs on student engagement at a middle school. They found that students enjoyed using the IWB, a finding reflected in numerous other studies [29, 32]. Beeland [15] also notes that the nature of the activity, the accompanying software and the level of engagement built into the lesson as factors that contributed to the positive attitudes, in addition to or rather than the IWB itself.

\subsection{Early Childhood Education and Technology}

Cause and Chen [33] note that the motivation to learn for kindergarten and primary school aged children increased when academic instruction was paired with the use of computing devices. However the literature examining the use of tablet devices in early childhood education is severely limited, with most research conducted in middle and senior school environments [33]. In their 2010 study, Cause and Chen examined the use of tablet devices to engage children in drawing and found that engagement increased with age, there was a high level of interest from the children, and they quickly developed ease using the stylus for drawing.

Matthews and Seow [34] also conducted a small study on very young children at a nursery and kindergarten in Singapore painting and drawing using a tablet. They noted that an adult companion was required to introduce the concepts of interacting with the device and suggested that the use of language between the adult and child while engaged in working on the tablet is worthy of future study.

There is a significant gap in the literature in regards to studying the implementation of iPads in early childhood education environments. Although the study by Bebell [20] mentioned above reported briefly on preliminary findings from kindergarten use of iPads in terms of literacy, it is not a rigorous study and it appears there has been no academic empirical research conducted on the use of iPads in any other early childhood education contexts.

\subsection{Engagement}

Engagement in early childhood education is shaped by approaches and frameworks. The Reggio Emilia approach is recognised internationally as a best practice approach [35]. It is not a teacher-led curriculum; instead it is an 'emergent' curriculum which 'emerges' over time and is led by the children, rather than the teachers [36]. It places emphasis on the child as a competent, unique and active social being, ready to interact with others and construct their own knowledge within the context of their environment and relationships with others. It utilises an emergent curriculum that provides opportunities, particularly through project work, for children to follow their interests, ideas and engage in authentic tasks. The role of the teacher therefore is not to transmit knowledge to the child, but instead to be a co-learner, collaborator and facilitator, creating an environment where learning can occur.

Framing the Reggio Emilia philosophy are national learning frameworks. In Australia this is known as the Early Years Learning Framework (EYLF), which has been developed to ensure implementers are applying the principles laid out in the United Nations Convention on the Rights of the Child, and Goal 2 of the Melbourne Declaration on Education Goals for Young Australians that states children will become successful learners, confident and creative individuals, and active and informed citizens [37]. EYLF has a specific focus on engagement through play-based learning which is in alignment with the Reggio Emilia approach.

Engagement is critical within the early childhood education domain and exists on many different levels. Successful engagement between educator and child, child and parent, and parent and educator are fundamental to the creation of the community environment espoused by Reggio Emilia. Other relationships requiring engagement within this context can include management, cooks, programming staff, and external providers.

\section{Discussion}

Initially, Cambourne's Conditions of Learning proposed that children acquire early facility with oral and written language most easily when certain conditions are present in their environments, both at home and school. It has now been applied to many different domains predominantly within the education field. The framework proposed in this section extends the role of Cambourne's Conditions of Learning in relationship to a model used in information systems research to understand the concept of a 'lifeworld' 
which refers to the "taken-for-granted" universe of daily social activities of members.

\subsection{Cambourne's Conditions of Learning}

Cambourne's theory for learning [38], consists of the following components (see Figure 1):

- Immersion: learners need to be immersed in content area

- Demonstration: learners need to receive many demonstrations of content area learning

- Expectation: learners are influenced by expectations, which are powerful shapers of behaviour

- Responsibility: learners need to make their own decisions about where, how, and what "bits" to learn.

- Use: Learners need time and opportunity to use and practice new learning in realistic ways

- Approximation: learners must be free to approximate desired study, as mistakes are essential for learning to occur

- Response: learners must receive relevant, appropriate, timely, nonthreatening feedback.

- Engagement: occurs when the learner is convinced that he or she is a potential doer of the demonstration, and that learning to practise it will fulfil a purpose of one's life.

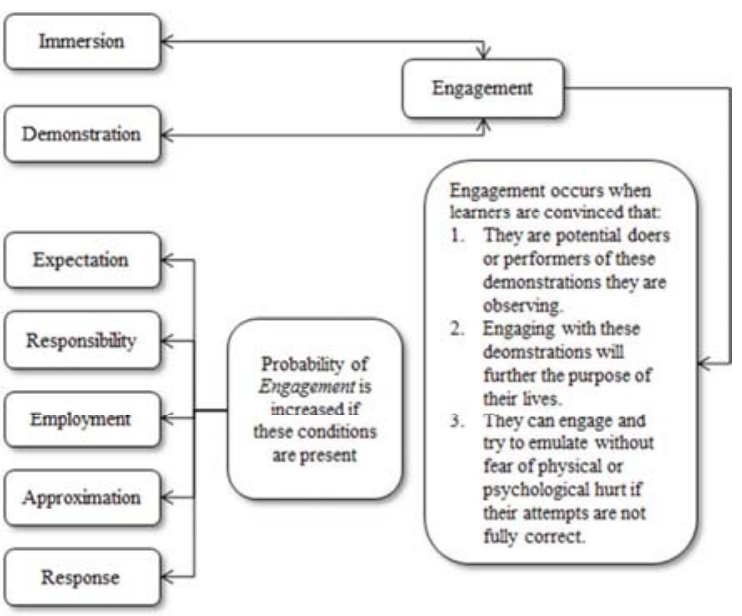

Figure 1. The conditions of learning

Immersion and demonstration must be accompanied by engagement, and the probability of engagement is enhanced when the conditions of expectation, responsibility, employment (use), approximation and response are present.

Cambourne's Conditions of Learning are well known in educational forums, especially in discussions around the pedagogy of literacy teaching, and it is no understatement to say that his model has stood the test of classroom educational practice and research [38-42]. Cambourne's Conditions of Learning have been studied in contexts involving the use of technology. Coffey [43] has applied Cambourne's Conditions of Learning to explicate learning processes in the use of ICT, namely in his own acquisition of the skill of tweeting, exploring ways to integrate technology into teacher training using iPads in pre-service teacher education and in the facilitation of collaborative learning environments across multiple locations. Larson [44] recognised and utilised the advancement of e-book technologies when she examined children's involvement with and response to digital readers. In the cases she studied, 'digital readers clearly provided new opportunities and extended possibilities for individual engagement with and interpretation of the text'.

Essential to Cambourne's conditions is the fundamental presence of a "Significant Other". The Significant other is someone who provides demonstrations, fives feedback, accepts approximations of conventions being learned, provides supporter and is often the main provider amongst others in the learning community.

\subsection{A Critical Perspective of Technology}

From an information systems perspective, it is significant to examine the use of a technology in the social context it is used in [45]. A useful way of creating this meaning is through the idea of a 'lifeworld'. Habermas [46], who belongs to the Frankfurt School of critical theory, believes that the lifeworld can be understood as being shaped by existing social and historical contexts. Using a critical approach allows any of the multiple interpretations that may exist about an issue to come to light $[47,48]$.

Figure 2 as represented by Mingers and Brockelsby [35] is grounded in Habermas' theories and suggests there are three worlds that make up the real life situations a person experiences. The material world is an objective reality, but observations and descriptions of it are dependent upon the social and personal worlds. The personal world is subjective and unique to the individual subject, where you can only attempt to appreciate interpretations of others. The social world is regarded as a shared intersubjectivity in that we can experience common events but will interpret them on a personal level.

In the context of this research, the material world is depicted by GIT. The personal world aligns with attitudes and personal experiences in relation to GIT. 
The social world is primarily aligned with the immersion and demonstration of GIT, but is also home to many other layers such as meaning, social practices, rules and resources. The lifeworld can be understood as the intersection of each of these worlds. Fully-engaged communication is the fundamental component. This will be explored in the following section.

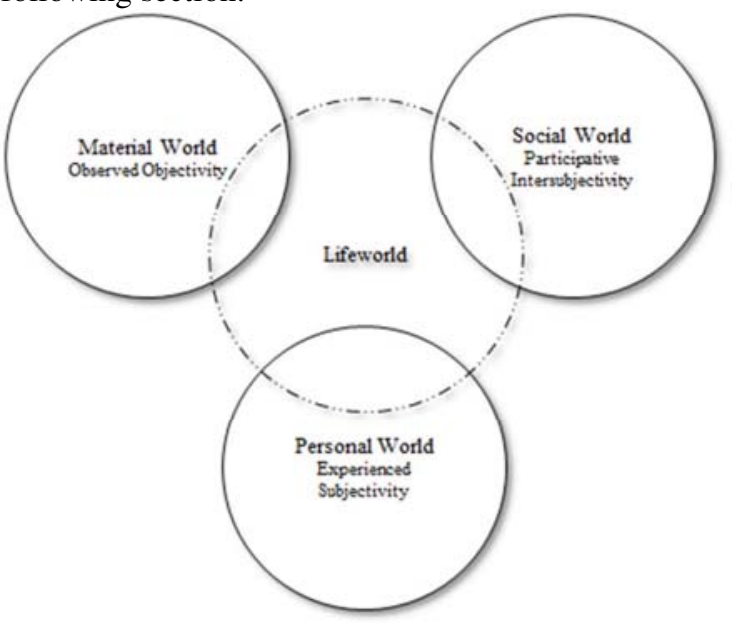

Figure 2. Three dimensions of problem situations

\section{Moving beyond Immersion and Demonstration}

From an educational viewpoint, besides the child as protagonist there are often other inter-actors. That is other children, teachers and parents who are part of the learning community along with the child. They may be instrumental in providing all of the other conditions necessary for learning [38], encouragement and belief that the child will learn and achieve successfully what they set out to achieve and learn, providers of specific demonstrations when needed, acceptance of approximated learning, feedback and so on. We conceive that the major difference now is that many of these conditions can appear as part of the GIT. Many applications used on GIT provide requisite demonstrations, opportunities for practice and use, feedback etc. Figure 3 illustrates the change of focus of the traditional conditions that appeared in Figure 1.

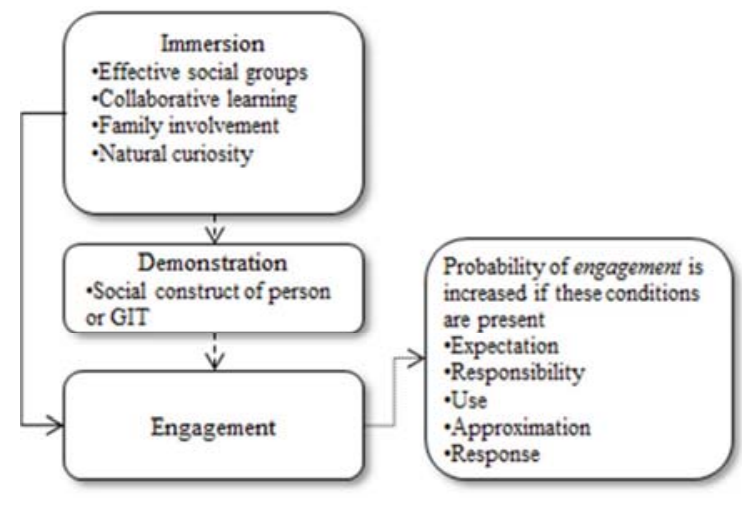

Figure 3. Amended conditions of learning

Immersion in potential knowledge, skills and understandings offered through interaction with GIT is foregrounded in this model to emphasise the overwhelming nature of the scope and potential of the world of information and knowledge available to the GIT user. GIT will be approached with natural curiosity and the user will be the protagonist in the environment according to their interests. The concept of immersion is likely to be influenced by teachers, parents and carers as 'Significant Others', as providers of demonstrations, contexts, investigative resources to stimulate curiosity, support, guidance and feedback; collaborative co-learners (apprentices); free choice experiences; family involvement and effective social groups.

Demonstrations may no longer be dependent on a person. Many demonstrations will be part of interaction with the GIT. Considerations such as the establishment of different environments that exist when working within the digital world need to be taken into account, influencing the social world. An example of this is the schema of "Me, We, See" by Heppell [49]. 'Me' is a personal, private space. 'We' is a community space that is secure; the members are known to each others. 'See' is a space that will give a world-wide audience.

\subsection{Fully-engaged communication and GIT}

We put forward that the presence of a "Significant Other" has been somewhat minimised with GIT. This is not to say that such persons are not necessary, but now there is almost an intimate, or even trusting relationship between the learner and the GIT, and the significant other may now have to share such roles with the resources contained within or built into the GIT.

With GIT used for learning opportunities in education, the connection of engagement to a learner's experience, background and interests is 
more than apparent. There are greater choices, and many possible demonstrations and models to engage with. The gates of access to possible engagement have widened and all but disappeared with the use of GIT.

The Reggio Emilia educational philosophy may hold one or more keys to the extension of Cambourne's conditions of learning. Within the Reggio Emilia philosophy increased emphasis is placed on the teacher as a learner alongside the child, a teacher-researcher, co-learner or apprentice. What is even more significant with the Reggio Emilia philosophy of learning is that the physical environment is considered as an additional teacher. If this environment has now become the GIT with its myriad demonstrations of real world learning, then is can now be considered to be part of the concept of "Significant Other".

Within the early childhood education environment, communication channels typically exist between the child, parent, educator and administrative staff illustrated in Figure 4. Other actors may also be present, and at all times, these communications are happening within the social world dimension where participative intersubjectivity shapes interactions, and the subjective personal world informs experiences. The use of GIT is envisioned to transform the communication channels that exist in early childhood education. Richness of interaction can be very well supported through collaborative technology.

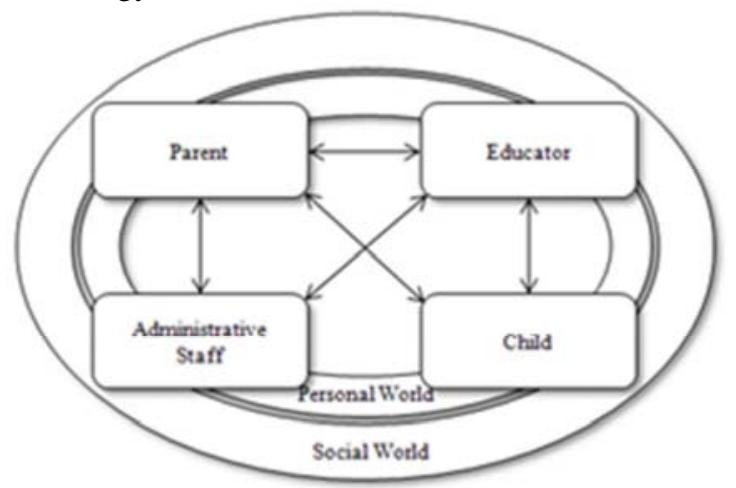

Figure 4. Communication channels in early childhood education

\subsection{Proposed Framework}

The framework of fully-engaged communication illustrated in Figure 4 extends Cambourne's Conditions of Learning using Mingers and Brockelsby's lifeworld model as a theoretical basis.
Where Cambourne considers the role of engagement a valuable endpoint, the framework of fully-engaged communication considers it an important component of the social world, contributing to the concept of fully-engaged communication. In this framework immersion and demonstration are not only accompanied by engagement, but engagement extends to fullyengaged communication within a lifeworld between the personal and social dimensions of the learner and the teacher as learner supported by the materiality of appropriate emerging technologies.

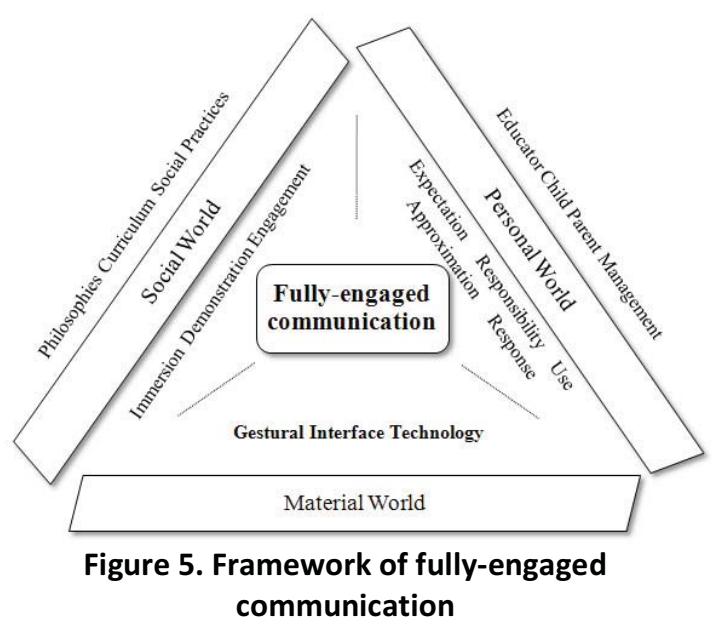

\section{Conclusion}

This paper has provided a framework for fullyengaged communication using gestural interface technology in early childhood education. The framework that has been put forward will be examined in an ongoing action research enquiry designed to understand how GIT is used to enhance engaged communication. Ultimately, for GIT to be used successfully and productively in early childhood education, a holistic understanding of the relationships between learners, teachers and immersive emergent technologies need to be understood for potential opportunities to be realised.

\section{References}

[1] Australian Curriculum Assessment and Reporting Authority, A. Australian Curriculum. 2010 [cited 201212 May 2012]; Available from: http://www.acara.edu.au/curriculum/curriculum.html.

[2] National Association for the Education of Young Children (2012) Technology and Interactive Media as Tools in Early Childhood Programs Serving Children from Birth through Age 8. 
[3] U.K. Department for Education. ICT curriculum. 2012 [cited 201223 April]; Available from: http://www.education.gov.uk/schools/teachingandlearning/ curriculum/a00199693/use-of-ict.

[4] United Nations Educational Scientific and Cultural Organisation. ICT in Education. 2011 [cited 201223 April]; Available from: http://www.unesco.org/new/en/unesco/themes/icts/.

[5] International Society for Technology in Education, National educational technology standards for teachers. 2000: International Society for Technology in Education.

[6] Norman, D.A. and J. Nielsen, Gestural interfaces: a step backward in usability. interactions, 2010. 17(5): p. 4649.

[7] SMART Technologies. SMART education solutions Early education. 2012 [cited 2012 10]; May]. Available from:

http://smarttech.com/us/Solutions/Education+Solutions/Ear ly+Education.

[8] Vazhayil, V. Apple Australia sold 1 million iPads in 2011. 2012 [cited 201201 May]; Available from: http://delimiter.com.au/2012/02/15/apple-australia-sold-1million-ipads-in-2011/.

[9] Qaisar, S. How Apple Is Trying To Revolutionize The Education Sector. 201211 April 2012 [cited 201202 May]; Available from: http://www.gamesht.com/2012/04/11/how-apple-is-tryingto-revolutionize-the-education-sector/.

[10] Apple Inc. Apple Reinvents Textbooks with iBooks 2 for iPad. 2012 [cited 201220 May 2012]; Available from: http://www.apple.com/pr/library/2012/01/19AppleReinvents-Textbooks-with-iBooks-2-for-iPad.html.

[11] Brian, M. Apple: 1.5 million iPads are used in educational programs, with over 20,000 education apps. 201219 January 2012 [cited 201202 May]; Available from: http://thenextweb.com/apple/2012/01/19/apple-1-5million-ipads-in-use-in-educational-programs-offeringover-20000-education-apps/.

[12] Catalano, F. When Technologies Collide: Consumer, K-12 and Higher Ed. 201217 April 2012 [cited 201228 April]; Available from: http://blogs.kqed.org/mindshift/2012/04/when-

technologies-collide-consumer-k-12-and-higher-ed/.

[13] Tippin, C. iPad Tablet Usage Statistics 2011. 2011 [cited 201229 January]; Available from: http://signalnews.com/ipad-tablet-usage-statistics-2011.

[14] Smith, H.J., et al., Interactive whiteboards: boon or bandwagon? A critical review of the literature. Journal of Computer Assisted Learning, 2005. 21(2): p. 91-101.

[15] Beeland, W.D. (2002) Student engagement, visual learning and technology: can interactive whiteboards help? Action Research Exchange 1.

[16] Kennewell, S. and A. Morgan, Factors influencing learning through play in ICT settings. Computers \& Education, 2006. 46(3): p. 265-279.

[17] Oviatt, S., A. Arthur, and J. Cohen, Quiet interfaces that help students think, in Proceedings of the 19th annual $A C M$ symposium on User interface software and technology. 2006, ACM: Montreux, Switzerland. p. 191200.
[18] Ferrer, F., E. Belvís, and J. Pàmies, Tablet PCs, academic results and educational inequalities. Computers \& Education, 2011. 56(1): p. 280-288.

[19] Milner, J., Tablet PCs: The write Approach. T.H.E. Journal, 2006. 33(9): p. 20-22,24,26.

[20] Bebell, D., S. Dorris, and M. Muir (2012) Emerging Results From The Nation's First Kindergarten Implementation of iPads.

[21] Manhattan Beach Unified School District (2012) MBUSD iPad Pilot Update.

[22] Higgins, S., G. Beauchamp, and D. Miller, Reviewing the literature on interactive whiteboards. Learning, Media and Technology, 2007.32(3): p. 213-225.

[23] Lee, M., Interactive whiteboards and schooling: the context. Technology, Pedagogy and Education, 2010. 19(2): p. 133-141.

[24] Ball, B., Teachign and learning mathetmatics with an interactive whiteboard. Micromath, 2003. 19(1): p. 4.

[25] Hall, I. and S. Higgins, Primary school students' perceptions of interactive whiteboards. Journal of Computer Assisted Learning, 2005. 21(2): p. 102-117.

[26] Kennewell, S. and A. Morgan. Proceedings of Student teachers' experiences and attitudes towards using interactive whiteboards in the teaching and learning of young children. in International Federation for Information Processing Working Group 3.5 Open Conference on Young Children and Learning Technologies. 2003. Sydney, Australia: Australian Computer Society, Inc.

[27] British Educational Communications and Technology Agency (2003) What the research says about interactive whiteboards.

[28] Goodison, T.A., Learning with ICT at primary level: pupils' perceptions. Journal of Computer Assisted Learning, 2002. 18(3): p. 282-295.

[29] Levy, P. (2002) Interactive Whiteboards in learning and teaching in two Sheffield schools: a developmental study.

[30] Glover, D. and D. Miller, Running with technology: the pedagogic impact of the large-scale introduction of interactive whiteboards in one secondary school. Journal of Information Techology for Teacher Education, 2001. 10(3): p. $257-278$.

[31] Kaufman, D.S., How Does the Use of Interactive Whiteboards Affect Teaching and Learning? Distance Learning, 2009. 6(2): p. 23-33.

[32] Bell, M.A. Update to Survey of Use of Interactive Electronic Whiteboard in Instruction. 2001 [cited 201212 May]; Available from: http://www.shsu.edu/ lis_mah/documents/updateboardinde x.htm.

[33] Cause, L.J. and D.W. Chen, A Tablet Computer for Young Children? Exploring Its Viability for Early Childhood Education. Journal of Research on Technology in Education, 2010. 43(1): p. 75-98.

[34] Matthews, J. and P. Seow, Electronic Paint: Understanding Children's Representation through their Interactions with Digital Paint. International Journal of Art \& Design Education, 2007. 26(3): p. 251-263.

[35] Mingers, J. and J. Brockelsby, Multimethodology: towards a framework for mixing methodologies. Omega, 1997. 25(5): p. 489-509. 
[36] Guyevskey, V., Interpreting the Reggio Emilia approach: Documentation and emergent curriculum in a preschool setting. 2006, York University (Canada): Canada. p. 151 p.

[37] Australian Government Department of Education Employment and Workplace Relations (2009) Belonging, Being and Becoming: The Early Years Learning Framework for Australia.

[38] Cambourne, B., The Whole Story Natural Learning and the Acquisition of Literacy in the classroom. 1988, London: Ashton Scholastic.

[39] Cambourne, B., Getting the Right Mix: Staff Development in the Literacy Strategy, in Meeting the Challenge NSW Literacy Strategy Conference Papers 1997, NSW Department of School Education: Sydney.

[40] Cossett Lent, R. (2006) Engaging Adolescent Learners: A Guide for Content-based Teachers.

[41] Hadfield, C., Towards a theory of critical viewing. 2005, University of Wollongong Thesis Collection.

[42] Harris, P., et al., Teaching reading in the primary years. 2006, Sydney: Social Science Press.

[43] Coffey, D. How did I use the iPad2? Facilitating Learning Environments 2012 [cited 2012 March]; Available from:

http://deltascape.blogspot.com.au/search/label/Cambourne.

[44] Larson, L.C., Digital Readers: The Next Chapter in EBook Reading and Response. The Reading Teacher, 2010. 64(1): p. 15-22.

[45] Doolin, B., Information technology as a disciplinary technology: being critical in interpretive research on information systems. Journal of Information Technology, 1998. 13(4): p. 301-312.

[46] Habermas, J., The theory of ocmmunicative action. 1984, Boston: Beacon Press.

[47] Cezec-Kemanovic, D., Doing critical IS research: the question of methodology, in Qualitative Research in Information Systems: Issues and Trends, E. Trauth, Editor. 2001, Idea Group Publishing: Hershey. p. 141-163.

[48] Trauth, E., Choosing qualitative methods in IS research: lessons learned, in Qualitative Research in IS: Issues and Trends, E. Trauth, Editor. 2001, Idea Group Publishing: Hershey. p. 271-288.

[49] Victoria Department of Education and Early Childhood Development (2012) In Your Hands: iPads for Learning - Classroom ideas for learning with the iPad. 